\title{
Research on the Path Mechanism and Reconstruction Mode of the Combination of Sports and Related Industries
}

\author{
Chen Fengcai \\ College of physical education, Shandong University of Technology, Shandong, China,255049
}

Keywords: Sports industry; industry integration; development; path

\begin{abstract}
The development of China's sports industry is just in its infancy, and there is still a long way to go from the market integration stage. However, with the continuous development of cross-industry mergers and acquisitions, technological innovation and strategic alliances, the integration of sports industry and related industries, more and more attention has been paid to the integration of sports and sports equipment, sports and media industries, tourism and other industries, which is the trend of the times and is an inevitable development trend. This paper introduces the significance of the integration and development of sports and related industries, the mechanism of the integration and development of sports industry and the prospect of the development of sports and related industries.
\end{abstract}

\section{Introduction}

The integration of sports and media, sports and tourism, sports and intermediaries, sports and sports services, and e-sports industries reflects the essence of industry integration of business integration, technology integration and market integration. The development of sports and related industries in constant integration has important practical significance. The integration of sports and related industries promotes the formation of more new products and services; the integration of sports and related industries raises the demand for the sports industry; the integration of sports and related industries brings new market environment with new members; sports and related Industry integration drives resources to re-optimize and allocate; the integration of sports and related industries can bring more employment opportunities and promote the development of sports human capital; the integration of sports and related industries will increase the value-added space of the sports industry[1].

\section{The status quo of the integration of sports and related industries}

In the information age, the trend of industrial integration is becoming more and more obvious, and the sports industry is no exception. In China, although sports is also considered a cultural phenomenon, its development is influenced by the market economy, some sports commoditization or the market, which has led to the formation of the sports industry. However, the theoretical concept of sports industrialization has not yet reached a consensus in China's academic circles, 
which inevitably has a negative impact on the theoretical research of the sports industry, and in turn will have a negative impact on the introduction of the correct sports industry policy in practice. We should define the concept of sports industry from a broad perspective, that is, the production and management of sports goods enterprises, which includes the production and management of sports material products and sports service products, among which sports service products mainly include fitness and entertainment, sports competitions. Performance, sports consulting, sports training, sports brokerage and other service industries, sports material products industry mainly sports equipment, sports clothing, sports food and beverage production and management. In this way, the expansion of the sports industry refers to the new products of the sports industry and other related industries. Sports play a role as a carrier or platform in this process. In this process, the intrinsic economic value of sports is perfectly interpreted. . The integration of the sports industry and related industries is the premise basis for the changes in the structure of China's sports industry and will lead the development of the sports industry[2].

\subsection{Integration of competition performance industry and media industry}

An important reason for the integration of the sports industry and related industries is the integration of technologies between industries brought about by technological advancement. The best example is the integration of competition, the performance industry and the media industry. Traditional sports events are just a single sporting event that has not been reported and disseminated by news broadcast media[3]. When modern media technology is applied to the sports industry, the reproduction and diversity of sports products, and even the rise of such a new e-sports movement. Therefore, the sports industry is a development model and an industrial organization form of different industries, improving the competitiveness of production efficiency and industrial economic development and the continuous improvement of information technology. The formation of sports media industry reflects the all-round integration of sports industry and media industry from technology to business to market.

\subsection{Integration of sports, fitness and leisure industry and tourism}

The sports industry integrates the fitness and entertainment industry, the leisure industry and the tourism industry, and it is developing rapidly around the world. The technical base and product characteristics of the fitness, entertainment, leisure industry and tourism industry are similar to meet the purpose of consumer entertainment and exercise. Their industry extends to other markets and extends to each other's market by expanding the product range[4]. The great value of sports tourism not only promotes the prosperity of sports tourism, but also attracts the attention of governments. Under the macro background of China's rapid economic development and social harmony and stability, large-scale international competitions have entered the Chinese market, bringing a good opportunity for China to develop the sports tourism industry. For example, in 1981, the first international marathon was held in Beijing, attracting a large number of domestic long-distance runners to the ancient capital Beijing to participate in this event. The number of participants in the 2007 Beijing International Marathon was 25,683, athletes and spectators. Not only can you participate in the competition, but you can also travel on vacation. This marathon event will promote the development of Beijing's local economy, promote the further development of sports tourism, and expand the spread of Beijing's urban image. The calculation formula for the development of sports-related industries is as follows, mainly in a standardized way. 


$$
\begin{array}{r}
x_{i j}^{*}=\frac{x_{i j}-\bar{x}_{j}}{s_{j}} \quad i=1,2, \ldots, n ; j=1,2, \ldots, p \\
\bar{x}_{j}=\frac{1}{n} \sum_{i=1}^{n} x_{i j} s_{j}^{2}=\frac{1}{n-1} \sum_{i=1}^{n}\left(x_{i j}-\bar{x}_{j}\right)^{2}
\end{array}
$$

\section{Sports industry development path reconstruction mechanism}

Today, the development of China's sports industry is still not mature. The phenomenon of sports industry integration is not obvious, and it has not yet entered the stage of market integration. However, we can be sure that the integration of technological innovation, cross-industry mergers and acquisitions, corporate and strategic alliances, sports industry and related industries will be more extensive and obvious. The integration of sports industry and related industries is an inevitable development trend. It is a new topic for the statistical work of the sports industry, the formulation of sports industry development policies, and the decision-making of investment and technological innovation behavior. Under the trend of industrial integration, relevant departments of the sports industry should take action to grasp the trend and adopt new development strategies for the development of the industry in the new situation[5].The weight of each influencing factor is as follows.

Table 1: Weight of each influencing factor.

\begin{tabular}{|c|c|c|c|c|}
\hline Index & Government & Industries & Talent & Product \\
\hline Weight & 0.382 & 0.403 & 0.112 & 0.103 \\
\hline
\end{tabular}

\subsection{Govermment regulation to relax industrial development}

The current regulatory framework will increasingly be challenged and challenged by industry convergence. Sports is an open platform, but there is still excessive government regulation in China's sports industry. In particular, competitive sports are almost completely controlled by the government, which hinders the conversion of more capital, technology and human resources into sports industry resources. Relaxing the government's regulation of the development of the sports industry is a necessary condition for promoting the integration of the sports industry.

\subsection{Strengthening learning and cooperation between industries}

With the extension of the sports industry chain, the sports industry sector has gradually formed similar characteristics and other tools with other industries. Only by establishing a platform for communication, learning and cooperation, tools for continuous learning and mastery, and the use of resources can promote the development of industrial integration.

\subsection{Cultivate high-quality inter-disciplinary talents}

Talent is the ultimate determinant of mastering technology, developing products and expanding markets. Only qualified personnel who are in need of training in the development of the sports industry in line with the trend of industrial integration development should be trained. China's talent market is more and more perfect, the training process mechanism is sound, various professional talents have gradually matured, and a large number of other professionals have entered the sports industry. For example, a large part of the staff of the Beijing Olympic Games Organizing 
Committee comes from all walks of life. However, this talent flow mechanism is not enough to ensure the huge demand for compound talents in the sports industry, and has professional knowledge after industrial integration. Therefore, it is imperative to explore and practice a compound talent training model.

\subsection{Create sports culture related products}

Taking tourism products as an example, on the basis of deepening cultural resources, how to make cultural resources into cultural tourism products is the key to industrial integration. In the initial stage of industrial integration, the cultural industry has the opportunity to integrate into all aspects of the tourism industry. At this time, industrial integration is in a recessive stage of development, which implies a huge opportunity for development. The government and enterprises can only identify and grasp the integration of culture and tourism industry. In order to smoothly integrate cultural resources into cultural products, the traditional culture can be revitalized while meeting the consumption needs of tourists. The integration of sports culture and sports tourism industry is guided by the changes of tourists' needs. The fundamental driving force is the change of tourism demand. The diversification of tourism methods and tourism types is the decisive factor for the integration of tourism industry. The rich cultural resources do not mean Industrial integration can be easily achieved. In fact, industrial integration is not only the need of industrial transformation but also under the guidance of market mechanism, that is, the products of industrial integration can not only meet the market demand, but also the development of the tourism industry itself. In the process of integrating cultural resources into cultural integration of cultural tourism products, adhering to market orientation helps to avoid the blindness of industrial integration and develop appropriate cultural products. In the process of integration of sports tourism and sports culture industry, the government and enterprises should not only innovate ideas into market research actions, but also use new technologies and methods to discover opportunities for industrial integration; they should also apply innovative thinking to the creation of cultural products. In the process, the development and design and implementation of any product requires the bold exploration and innovation of the implementer. If there is no innovation, the effect of product development and implementation will be affected.

\section{Conclusions}

The development of China's sports industry is just in its infancy, and there is still a long way to go from the market integration stage. However, with the continuous development of cross-industry mergers and acquisitions, technological innovation and strategic alliances, the integration of sports industry and related industries is coming. The more attention is paid, the integration between sports and sports equipment, sports and media industries, tourism and other industries is the trend of the times and is an inevitable development trend.

\section{References}

[1] Nobuyuki Ogawa. Active Learning Strategy at a Collegewide Level in NIT, Gifu College[J]. Procedia Computer Science,2018,126.

[2] Dena Fehir. Hamilton bans contractor from bidding for two years but still not enough: Merulla[J]. Daily Commercial News,2017,90(62).

[3] Vanessa Ratten,João J. Ferreira. Sport Entrepreneurship and Innovation [M].Taylor and Francis:2016-11-15.

[4] Kelly Weidner,Anjali Bal,Samantha Rains,Christopher Leeds. Tattooing and brand sponsorship: how far is too far [J]. Journal of Product \&amp; Brand Management,2016,25(4).

[5] Denise Linda Parris,Stephen L. Shapiro,Jon Welty Peachey,Josh Bowers,Adrien Bouchet. More than competition: 
exploring stakeholder identities at a grassroots cause-related sporting event[J]. International Review on Public and Nonprofit Marketing,2015,12(2). 